\title{
HVDC system for National and Cross Border Grid Interconnections in Saudi Arabia
}

\author{
M.A. Rahman ${ }^{1}$, I.Ashraf ${ }^{2} *$, Hamed D. Alsharari ${ }^{3}$ \\ ${ }^{1}$ AREVA T\&D, Al Khobar, Kingdom of Saudi Arabia, \\ $*^{2}$ Department of Electrical Engineering, A.M.U., Aligarh India [EED, College of Engineering, TU, Madina, KSA] \\ ${ }^{3}$ Department of Electrical Engineering, College of Engineering, KSU, Riyadh, KSA [EED, College of Engineering, JU, \\ Aljouf, KSA]
}

\begin{abstract}
Electricity grid interconnections play a key role in the history of electric power system development. This paper reviews the present status and future prospect of HVDC system in national and inter-national interconnection, infrastructure and electricity exchange in Saudi Arabia in particular and gulf region in general. Development of power system and evolution of national grid interconnection in Saudi Arabia along with case study of newly commissioned GCCIA back-to back HVDC system have also been incorporated. Viability of new HVDC interconnection in Saudi Arabia and Gulf region has been presented keeping in mind the technical, environmental and socio-economic aspect of interconnections. This interconnection amongst the regional load dispatch centers as well as NLDC of Egypt, Yemen, Interconnection Control center (ICC) within the Gulf Co-operation Council Interconnection Authority (GCCIA) shall be able to increase the overall efficiency of the transmission system.
\end{abstract}

Keywords: Grid Interconnection, HVDC, Gulf Cooperation Council, Electricity deregulation, Competitive Market, NLDC, Economic exchange, Reserve Capacity, Stability and Reliability.

\section{Introduction:}

High Voltage Direct Current (HVDC) system plays vital role in today's power system around the world and will continue to contribute more with the advent of Smart Super Grid in the future. Over the past few decades expanding power grids has proven to be both economically and environmentally desirable. The utilization of time zone, seasonal diversity that may exits between adjacent power systems can postpone or eliminate the necessity of building redundant generation units. This paper reviews the present status of power system in Saudi Arabia and envisages evolution of national grid with increasing regional interconnections. Benefits of using HVDC system or Hybrid AC/DC system has been discussed from different projects in order to create secure, stable and reliable grid for the deregulated electricity market.

\section{Potential Benefits of Grid Interconnections}

The driving force for the development of power systems is the on-going increase of electrical power demand. Therefore, power system develops from the regional to national system. Strong environmental constraints, natural energy resources far away from load centers and severe right of way constraints combined with techno-economic advantages, leads to large continental systems by applying interconnections to the neighboring systems. The operation of power grid as an interconnected system usually leads to improved system Security and economy of operation [1].

Interconnection of power systems may offer important technical, economical and environmental advantages such as:

- Reduction of the necessary reserve capacity in the system by reserve sharing which may lead to reduced investment in generation capacity or postpone the need to add new capacity.

- Improving reliability and supply security.

- Improving load factor by increasing load diversity, utilization of time zone and seasonal diversity.

- Reduction of losses by an optimized system operation, economic power exchange diversity of generation mix and environmental dispatch.

- Coordination of maintenance schedules which permits planned outages of generation and transmission facilities to optimized overall cost and reliability.

- Utilization of most favorable energy resources with flexibility of building new power plants at favorable locations.

The liberalization within power industry additionally supports system interconnections to enable the exchange of power among the regions or countries and to transport cheaper and more ecologically suitable energy over long distances to the load centers. Some costs and benefits of interconnections are difficult to quantify, but as a rough figure of merit it has been estimated that interconnections in North America have resulted in an overall annual cost savings of $\$ 20$ billion in the 1990s, 
and that the Western European interconnection has resulted in reduced capacity requirements of 7-10\% [2]. As far as Arab countries are concerned, the forecast installed capacity in 2015 is $203 \mathrm{GW}$ with reserve capacity expected to be in the order of $20 \%$. Lowering reserve capacity to $12 \%$ from $20 \%$ through grid interconnection, will not only save capital cost of US $\$ 11$ Billion by saving an additional capacity construction of $12 \mathrm{GW}$, but will also have major impact on reducing pollution, operation and maintenance expenses.[3]

International grid interconnection projects may yield significant social benefits derived from enhanced supply of electricity to some or many groups in the nations participating in the project. Among these benefits are: better power quality, more reliable power, and more widespread availability of electricity to communities. Greater availability of affordable electricity can provide more opportunities for education, improvements in health care, industrial growth, development of employment opportunities, and reduction of difficult and labor-intensive tasks, all of which can contribute to sustainable development.

\section{Technical complexities and risks of grid interconnections}

The fact that interconnections between power systems are increasingly common does not imply that they are as simple as connecting a few wires. Interconnections obviously entail the expense of constructing and operating transmission lines and substations. Interconnections also entail other costs, technical complexities, and risks. Considering the current transmission costs of about 1-2 cents per $\mathrm{kWh}$, the reasonable distance to transmit power still economically could be therefore in the range of up to $3000 \mathrm{~km}[4]$.

Interconnecting two $\mathrm{AC}$ systems using $\mathrm{AC}$ tie lines will require high degree of technical compatibility and the automatic generation controllers of both systems to be coordinated using the tie line power and frequency. However, the interconnected AC systems with control coordination are still subjected to some operational problems such as large oscillations which may lead to equipment tripping [5-6], high short circuit levels, loop flow, voltage collapse, dynamic and transient instability, or cascading outages due to propagated disturbances. Major blackouts in North America and Europe in 2003 demonstrated, large-scale disturbances can propagate through interconnections and result in cascading outages, bringing down systems that had previously been functioning normally. A wide range of new and emerging technologies such as HVDC and Flexible Alternating Current transmission System (FACTS) could assist in significantly minimizing the occurrence and impact of widespread blackouts [7]. Using the DC line as a tie line would eliminate most of the above mentioned problems as the DC line is insensitive to the frequency and it would connect two asynchronous systems and isolate the system disturbances [8].

\section{Benefits of Grid Interconnection with HVDC}

The interconnections are mostly realized by asynchronous/synchronous links where such solutions are technically feasible and economically justified. On the other hand HVDC links often offer technically better and more economical solutions. HVDC transmission systems provide attractive and even unique features for bulk power systems, for example, long distance bulk power delivery, long submarine cable, voltage stabilization, asynchronous interconnections and other applications for special circumstances [9]. Fast and full power controllability, no necessity for common frequency, stable operation even at small power rating of interconnection, improvement of dynamic conditions in the ac systems by modulating transmitted power, transmission of scheduled power independent of system conditions in the ac systems makes HVDC an viable option to be utilized for solving any of a number of challenges such as:

- Interconnection of systems employing different frequency characteristics not compatible with synchronous connection.

- Avoiding undesirable loop flows in parallel ac transmission lines.

- Control of interchanges, possibly with additional signals, to ensure system stability margins are kept.

- Controlling the power flow and avoiding overloading to prevent cascading trips, thus limiting system breakup under severe contingencies.

- Limit short circuit increase.

A significant advantage of the HVDC interconnection is that, power can be transmitted directly between two locations without overloading the existing system. Therefore, HVDC can essentially improve the reliability of complex interconnected systems. Furthermore, HVDC is a firewall against cascading disturbances and in this fashion, it prevents blackouts. For these reasons, in some part of the world, HVDC or hybrid interconnections, consisting of AC and DC interconnections, have already become the preferred solution.

A large number of example worldwide shows that HVDC is quite a suitable solution. However, in many situations, hybrid solutions for interconnection are more advantageous: a synchronous high voltage AC link, supported by an additional HVDC link. In cases where the synchronous interconnection is technically at the limit, HVDC can support the operation of the interconnected systems and thus make the synchronous AC link more reliable [10]. The integration of HVDC transmission into an AC system started with the Pacific Intertie Project in USA. The reason for this application is a long 
transmission distance and a weak parallel AC system along the western coast of USA. HVDC also effectively enhances the dynamic conditions in the AC system [11]. The second largest HVDC, integrated into an AC system is Rihand-Dadri transmission in India, built to interconnect regional systems and to by-pass the weak $400 \mathrm{kV}$ AC system and to bring power directly from large power plants in the area of Rihand to the load center of New Delhi [12].

\section{Development of Saudi power system}

Electric power is an essential tool for modern economic development. The combination of Saudi Arabia's rapidly expanding population and industrial base has increased the demand on electric utilities averaging 5 to $7 \%$ annual growth as depicted in Fig $\{1\}$. As per SEC (define?) 2009 annual report, the installed capacity of Saudi Arabia is 44,582MW where as peak load observed in 2009 was 41,200 MW [13].

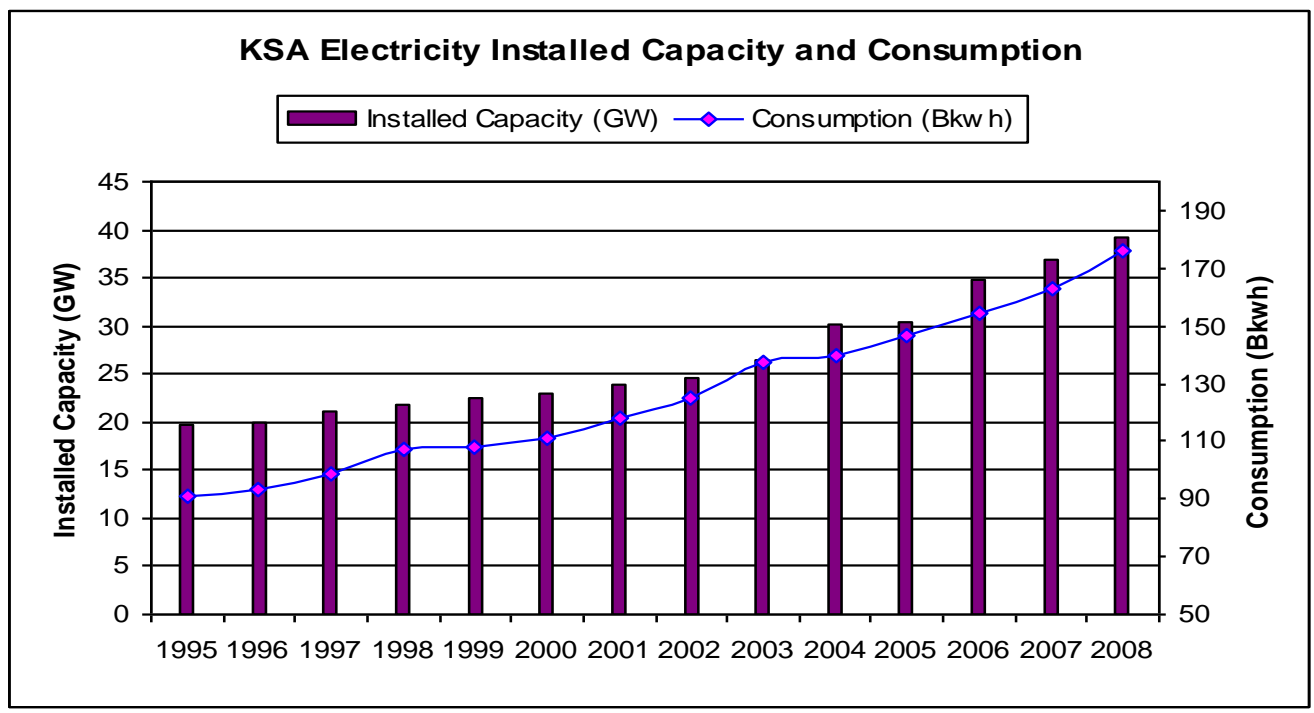

Fig \{1\}: KSA electricity Installed Capacity and electricity consumption [14].

\section{Power System Reform in Saudi Arab}

Saudi Arabia's power sector, including generation, transmission and distribution, has traditionally been dominated by the partly state-owned Saudi Electricity Company. As part of the reformation process, the Electricity Services Regulatory Authority (ECRA) was established in November 2001. The ECRA is responsible for regulating the supply of electricity, issuing licenses for electricity projects, ensuring compliance with conditions of licenses, and the protection of rights of consumers, investors, producers, transporters and distributors. However, In July 2002, the Supreme Economic Council passed a resolution setting out a framework for private sector involvement in developing mega-scale integrated Independent Water and Power Projects (IWPPs), and since that time the sector has become increasingly liberalized. Saudi Arabia aims to attract private sector investment for up to 60\% equity in IWPP projects, with the remainder split between Public Investment Fund (PIF) and the SEC. Apart from this, ten percent of power generation is planned to come from independent power projects (IPPs) in the next decade. The formations of Marafiq in the industrial cities of Jubail \& Yanbu and the establishment of the Water \& Power Corporation (WEC) in the western province of the country have been a major boost to privatization. Currently, major industrial consumers are allowed to generate their own power and sell off excess power to SEC transmission.

A proposed electricity sector reforming plan for a three-stage electricity market evolution over the period 2008-2016 was developed. The plan consists of:

- Unbundling \& Generation Competitions (2008-2010): It involves the unbundling of the SEC into operationally independent generation, transmission, and distribution companies, and the introduction of competition in power generation. It will see the creation of four generation companies from existing SEC assets, a power procurement company to act as a single-buyer, and a grid company to own the transmission system and act as an independent system operator.

- Wholesale Competition (2010-2013): This shall introduce wholesale competition, increase the size of the parallel market, create distribution companies (owned by the SEC), establish a spot market allowing non-discriminatory access by large electricity customers to the grid and implement a wheeling tariff et by ECRA. 
- Retail Competition (2013-2016): This will introduce a full wholesale electricity market being operated by an independent system operator. Both generation and distribution companies will have independent roles in the market with a restricting role for the single buyer. The concept of independent system operator (ISO) as an unbiased coordinator to balance reliability with economics has also emerged in deregulated electricity market [15-16].

Load forecast of Saudi Arab as shown in Figure 2 depicts that anticipated load in 2020 for Saudi Arabia will be around 75 $\mathrm{GW}$, which is approximately $88 \%$ increase from the present valve within 10 years. Generation plan focused on boosting the generation capacities with target of $15 \%$ reserve in Electric power generation capacity by 2020 . Based on the study of future generation options for the interconnected network, it has adopted the steam power plant for the coastal areas and the combined-cycle or gas power plants for the interior territories. Based on this arrangement, eight main power plants are planned /executed in Qurayyah, Ras Al-Zor, South Uqair in the Eastern Region. Eleven Power Plant in Riyadh, Rabigh and South Jeddah and in the Western Region, Shuqaiq Power Plant in the Southern Region and Dhabaa Power Plant in the North Western Region. In order to cope up with increasing demand new generating units with total capacity addition of 9055 MW by 2012, 7190 MW by 2014, 10800 MW by 2016 are being planned to be installed. Independently, Saudi Aramco is building a series of co-generation plants at oil and gas installations throughout the country in order to reduce drain of the energy sector on the national grid. Installation of two co-generation units with a combined capacity of $300 \mathrm{MW}$ at Khursaniya and Shaybah mega-projects were installed as a part of example.

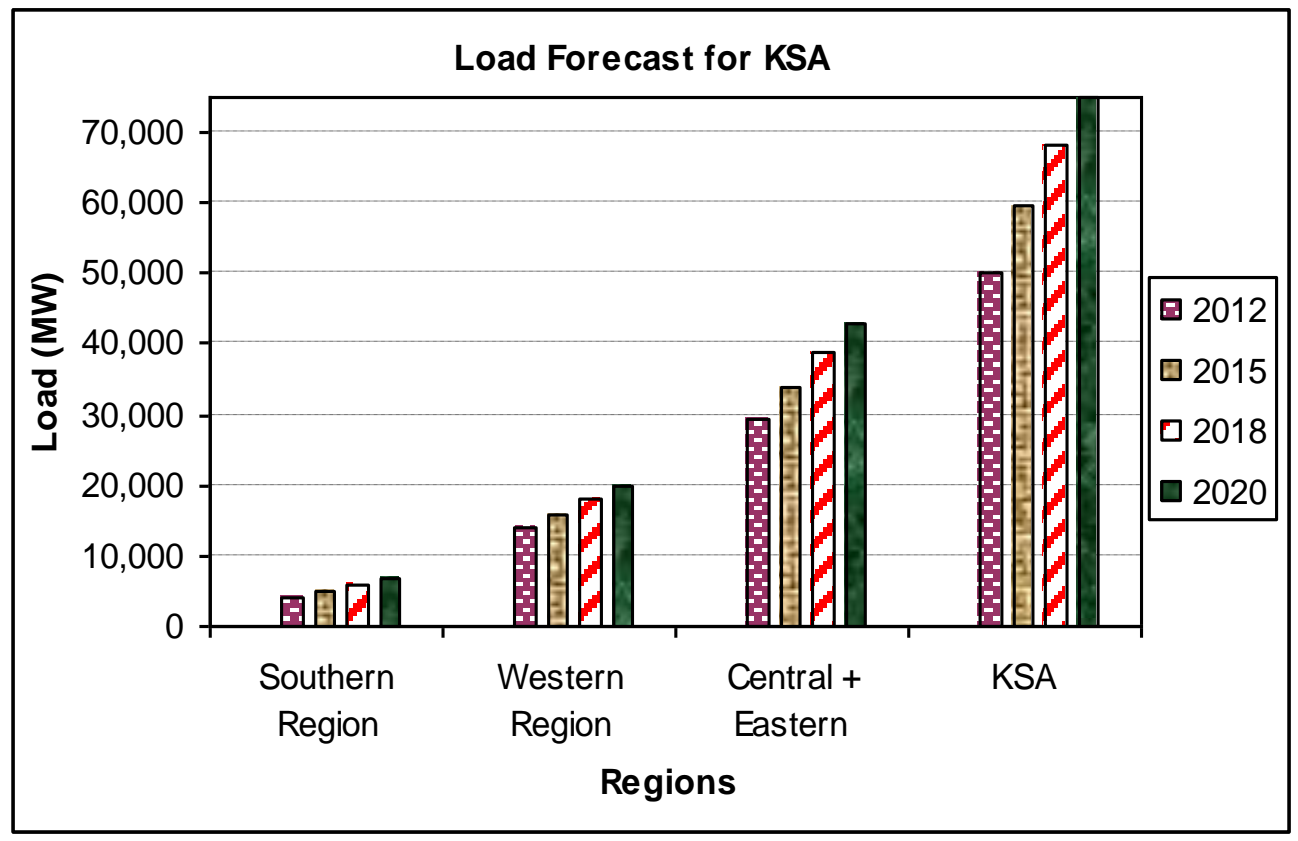

Fig. [2] Load forecast of the Saudi Arab [14]

\section{Existing Grid structure and future expansion}

The network of the transmission system of the Saudi Electricity Company (SEC) is mainly of two sub-transmission areas which are the Consolidated Transmission Area (CTA) and the Developed Transmission Area (DTA). The CTA bulk transmission system comprises two major subsystems namely Central Operating Area (COA) and the Eastern Operating Area (EOA) which are tied together through two double circuits $380 \mathrm{kV}$ and one double circuit $230 \mathrm{kV}$ lines. One double circuit $380 \mathrm{KV}$ interconnection is currently under execution and another is planned. On the other hand, the DTA comprises other two major subsystems namely Western Operating Area (WOA) and the South Operating Area (SOA) which are completely isolated areas (Figure 3). 


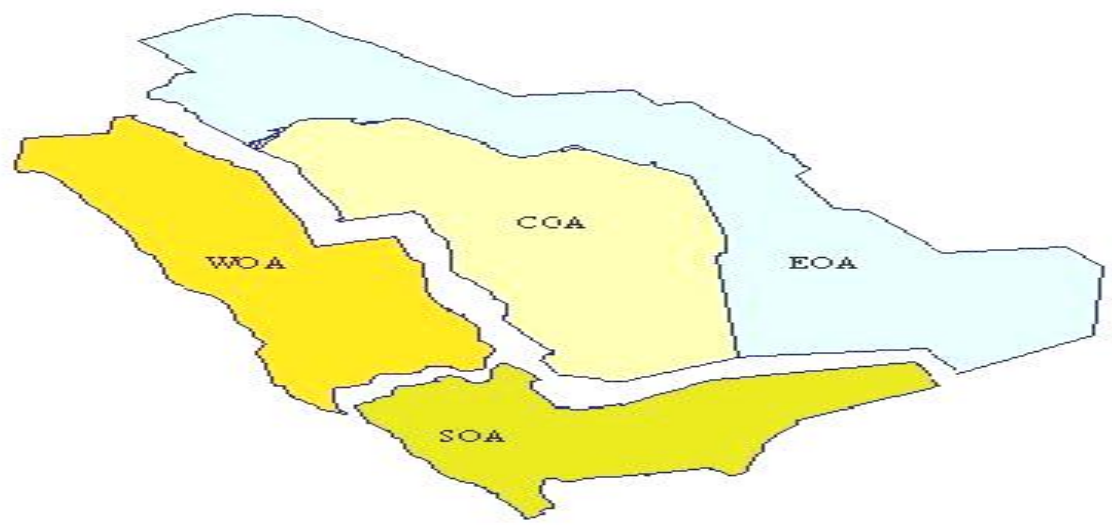

Fig 3 Electrical Regions of KSA

In recent years, the increased load has lead to shortages, blackouts and power rations in various parts of the kingdom. Major fault incidents experienced by SEC transmission network were $17 \%$ of the total 2005 interruptions and analysis recommendations to decrease the possibility of fault incidents re-occurrence and to improve the supply continuity. Majority of recommended actions are to be taken for Transmission System Reinforcement and Protection system categories [17].

Besides generation, Saudi Arabia also requires additional investment in power transmission. Options for the expansion of electric power transmission networks include projects for connecting both the currently executed and planned generation units with the Company's overall electrical network, projects for boosting the electrical connection among the regions of the Kingdom to form a consolidated network, and projects for ensuring continuity of electric service and the stability of the electric system throughout all regions of the Kingdom.

The most important projects for connecting new power stations include the introduction of a new $380 \mathrm{kV}$ network at the North Western Region of the Kingdom to connect the proposed Dhabaa Power Plant to Tabuk and Al-Ula/Al-Wajh and then connecting thereof to the network of the Western Region.

Projects for Grid Strengthening and interconnecting the regions of Saudi Arab includes 380kV lines between Al Qassim-Al Madina in 2011, Hail-Al Joiuf in 2012, Jizan-Nazran in 2012, Fifth interconnection between EOA-COA in 2013, Bisa-Wadi Aldowaser in 2014, Madina-Hail in 2015 and COA-WOA Bipole HVDC interconnection in 2017 are to name a few. Apart from above Interconnection lines, establishment of more than twenty-five (25) 380kV transmission substations all over the Kingdom with more than 22 support projects for the existing $380 \mathrm{kV}$ substations and more than 250 sub-transmission substations of $132 \mathrm{kV}, 115 \mathrm{kV}$, or $110 \mathrm{kV}$ capacities in various areas of the Kingdom are needed to fulfill rapidly increasing electricity demand by 2020 [14].

\section{Case Study of GCCIA}

Recognizing the benefits of interconnection of their power grids, the six Arab states of Kuwait, Saudi Arabia, Bahrain, Qatar, United Arab Emirates (UAE) and Oman, decided to build an AC interconnection of the $50 \mathrm{~Hz}$ systems of Kuwait, Bahrain, Qatar, UAE and Oman with a back-to-back HVDC interconnection to the $60 \mathrm{~Hz}$ Saudi Arabian system [1820]. The interconnection was justified based on reserve sharing between the systems and cost of project being beard by the participating systems in proportion to their estimated reserve capacity savings [21-26].

The principal benefits due to the interconnection arise from the sharing of reserves between the systems and the consequential reduction in the installed generating capacity and associated operating and maintenance costs in the GCC countries. The capacity benefits to 2028 MW for Phase-I are shown in Table 1.

Table 1: Capacity Benefits of GCCIA inter connection to member states [22].

\begin{tabular}{|l|l|l|l|l|l|l|}
\hline Country & \multirow{2}{*}{$\begin{array}{l}\text { Load } \\
\text { (MW) }\end{array}$} & \multicolumn{2}{|l|}{ Total Installed Capacity (MW) } & $\begin{array}{l}\text { Cumulative } \\
\text { Benefit (MW) }\end{array}$ & $\begin{array}{l}\text { Reserve } \\
\text { (MW) }\end{array}$ \\
\cline { 3 - 7 } & & Isolated & Interconnected & Interconnected & Isolated & Interconnected \\
\hline Kuwait & 27017 & 30397 & 29066 & 1331 & 3380 & 2049 \\
\hline Saudi Arabia & 23210 & 26361 & 24752 & 1609 & 3151 & 1542 \\
\hline
\end{tabular}




\begin{tabular}{|l|l|l|l|l|l|l|}
\hline Bahrain & 4989 & 5782 & 5494 & 288 & 793 & 505 \\
\hline Qatar & 4649 & 5427 & 5060 & 367 & 778 & 411 \\
\hline Total & 59865 & 67967 & 64372 & 3595 & 8102 & 4507 \\
\hline
\end{tabular}

\section{Sharing of the costs of the interconnection project}

It was agreed amongst the countries to share the costs of the Interconnection in proportion to the reserve capacity savings. Considering the time value of money and the capacity savings occurrences at different points of time, it was agreed to share the costs in proportion to present value of the capacity savings.

Table 2: Project Cost Sharing [23]

\begin{tabular}{|l|l|l|}
\hline Country & Phase I (\%) & $\begin{array}{l}\text { Phases II } \\
\text { \& III (\%) }\end{array}$ \\
\hline Kuwait & 33.8 & 26.7 \\
\hline Saudi Arabia & 40.0 & 31.6 \\
\hline Bahrain & 11.4 & 9.0 \\
\hline Qatar & 14.8 & 11.7 \\
\hline UAE & - & 15.4 \\
\hline Oman & - & 5.6 \\
\hline Total & 100 & 100 \\
\hline
\end{tabular}

\section{Benefits of the interconnection project}

The principal benefits that can be achieved through interconnection (Figure 4) are:

- Interconnections result in the requirement for lower installed capacity in each of the systems (due to reserve sharing) while still supplying the load with the same (or better) level of reliability.

- Interconnections can permit larger and more efficient generating units to be installed on the individual systems.

- Interconnections enable systems to share operating (spinning) reserves so that each system can carry less spinning reserve.

- Interconnections enable interchange of energy between systems resulting in a lowering of total operating costs.

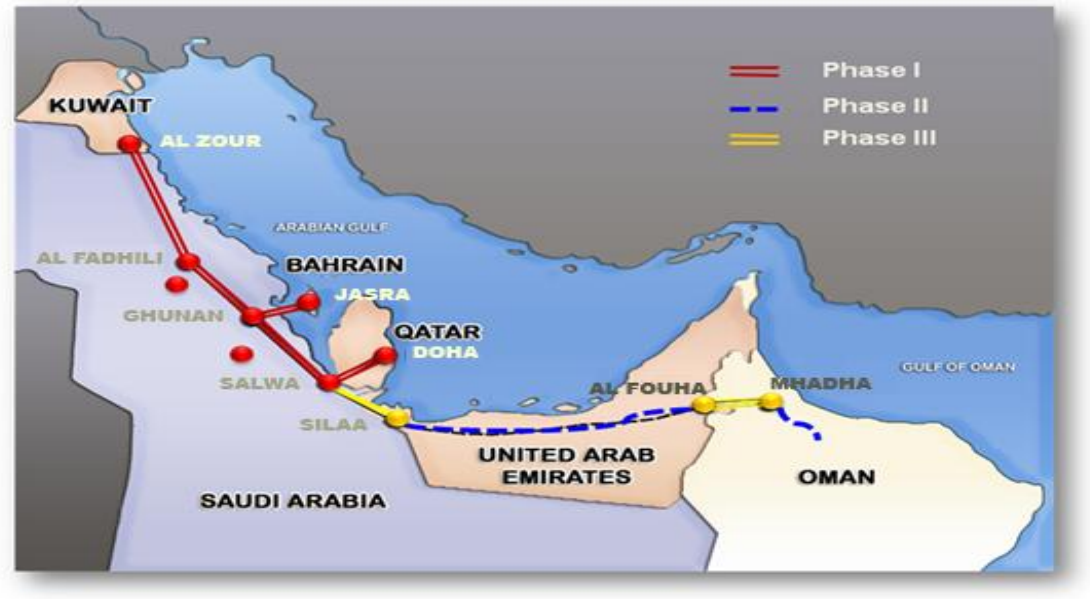

Fig. 4 : GCCIA Interconnection

Phase I: Interconnection of the Northern Systems (Kuwait, Saudi Arabia, Bahrain and Qatar) is in operation since the middle of 2009 which consists of:

- Double-circuit $400 \mathrm{kV}, 50 \mathrm{~Hz}$ line from Al Zour (Kuwait) to Ghunan (Saudi Arabia) with an intermediate connection at Fadhili (Saudi Arabia) and associated substations.

- HVDC back-to-back interconnection between GCCIA 50Hz system \& Saudi Arabia 60Hz system at Fadhili.

- Double circuit $400 \mathrm{kV}$ comprising overhead lines and submarine link from Ghunan to Al Jasra (Bahrain) and associated substations.

- Double circuit 400kV line from Ghunan to Salwa (Saudi Arabia) and associated substations. 
- Double circuit 400kV line from Salwa to Doha South (Qatar) and associated substations.

- Control Centre located at Ghunan.

Phase II: The internal interconnection of the Southern Systems (UAE and Oman) to form the UAE National Grid and the Oman Northern Grid (GCCIA is not involved in this Phase).

Phase III: Interconnection of the Northern and Southern Systems in 2010.

- A double circuit 400kV line from Salwa to Ghuwaifat (UAE) and associated substations.

A double and a single circuit 220kV line from $\mathrm{Al}$ Ouhah (UAE) to $\mathrm{Al}$ Wasset (Oman) and associated substations.

\section{HVDC Back-to-Back Converter Facility}

The basic objective of the converter facility is to allow reserve sharing between the electrical power systems of participating member states (systems at $50 \mathrm{~Hz}$ and $60 \mathrm{~Hz}$ ) and, as a secondary objective, to permit power transfer between the member states where such transfer has economic benefits. To achieve effective reserve sharing it has Dynamic Reserve Power Sharing (DRPS) Control which ensures that up to $1200 \mathrm{MW}$ of active power will be able to be transferred from $50 \mathrm{~Hz}$ to $60 \mathrm{~Hz}$ systems and vice versa with sufficient speed of response and accuracy of control to stabilize the interconnected systems following the established critical loss of generation event within either system [25,26]. Provided that the ability to effectively share reserve is not compromised, the converter facility also allows economic interchange of up to 1200MW of active power between the systems in either direction. In order to ensure the availability of 1200MW of inter-system real power transfer capability, three independent 600MW back to back converters is installed and commissioned in mid of 2009 which is running successfully[27,28].

\section{Viability of HVDC interconnections Saudi-Egypt HVDC Inter connection}

The electricity utilities of kingdom of Saudi Arabia and Egypt has completed the preliminary feasibility study of an interconnection between two country national grids and are now proceeding with the implementation. Presently engineering consultancy has been awarded which includes route selection, system and design studies for the link which would be able to transfer $3000 \mathrm{MW}$ of power. The purpose of this interconnection is to provide Egypt and the Kingdom of Saudi Arabia with necessary flexibility to share their capacity and trade energy in a commercial manner during normal operation an to provide mutual back up assistance during emergency operating conditions. The project would provide an HVDC link between Saudi Arabia and Egypt. This would be a Bipolar $+/-500 \mathrm{kV}, 3000 \mathrm{MW}$ muliterminal line approximately $1500 \mathrm{Km}$ long (including around $25 \mathrm{~km}$ Submarine cable) between Badr Substation (Egypt) and Medina-East Substation (Saudi Arabia) with and intermediate terminal point at Tabuk (Saudi Arabia).

\section{Regional Interconnection}

Several Projects for Grid Strengthening and interconnecting the regions of Saudi Arab are planned with 380kV lines. Major regional interconnection project incorporating Bipolar HVDC interconnection between Central Operating Area and Western Operating Area of Saudi Arab is planned to be operational in 2017[29].

\section{Saudi -Yemen inter connection}

The Saudi southern power network is isolated and its demand is expected to grow rapidly due to the area's economic developments such as Jazan Economic City. Yemen's power system could be a reliable source of power supply to the southern network of Saudi Arabia. This is due to the potential of Yemen's proven natural gas reserves which could be utilized in power generation. Besides, Yemen is conducting intensive natural gas exploration that could lead to more efficient power generation and/or feasible energy integration initiatives. In respect to interconnection studies, in 2007 a study of interconnection between Saudi Arabia with Yemen was completed [30,31]. The study concluded the feasibility of interlinking the two systems and presented the viable solution(s) from both economic and technical perspectives. Further, this link has to be asynchronous inter connection which can only be realized with the help of HVDC system either by back to back station or HVDC transmission scheme [32,33].

\section{CONCLUSIONS}

HVDC gives many benefits for transmission interconnections, both within synchronous areas and across their asynchronous borders. These benefits may be economical, environmental or technical. The ability of HVDC systems to control power flow and prevent propagation of severe disturbances, thus limiting blackout extension and ability to maintain independence of interconnected networks is of prime importance when the two systems have different regulatory procedures and also for technical reasons, if the load frequency control regimes are not compatible. The prospect of HVDC interconnection within Saudi Arabia and with neighboring countries is a viable alternative for the future grid security. Optimal power trading between Saudi Arabia and neighboring countries interlinked by HVAC/HVDC transmission schemes has been one of the 
IOSR Journal of Engineering

Apr. 2012, Vol. 2(4) pp: 529-537

foremost aim taking into consideration the linkage of Saudi Arab, Egypt, Yemen, GCCIA owned Qatar Kuwait, Bahrain, UAE, KSA and Oman interconnections.

\section{References}

[1] P Kumar and Ibraheem, "Optimal AGC Regulator Design of a Two-Area Power System with Parallel ac/dc Links”. Proceeding of Iranian Conference on Electrical Engineering (ICEE-1993), Iran, May 1993, pp 75.

[2] UN Department of Economic and Social Affairs Division for Sustainable Development, "Multi Dimensional Issues in International Electric Power Grid Interconnections", Economic and Social Affairs , United Nations Publication, New York, 2006, pp15-30.

[3] Mohammad A Dashash, Emad Ragaban. “Energy Cost Optimization Through the Implementation of Cogeneration and Grid Interconnection", CIRED 2007, 19 ${ }^{\text {th }}$ International Conference on Electricity Distribution, Vienna,21-24 May 2007, Session X,. paper 004, pp1-5.

[4] Günther Beck, Wilfried Breuer,Dusan Povh, Dietmar Retzmann, Erwin Teltsch "Use of FACTS and HVDC for Power System Interconnection and Grid Enhancement" , POWER-GEN Middle East Conference, Jan30Feb1,2006, Abu Dhabi, UAE.

[5] M. A. Abido, , "Power System Stability Enhancement Using Facts Controllers: A Review", The Arabian Journal for Science and Engineering, Volume 34, Number 2B April 2009

[6] F. deMello and C. Concordia, "Concepts of Synchronous Machine Stability as Affected by Excitation control", IEEE Trans. PAS, 88(1969), pp. 316-329.

[7] G. Andersson, P. Donalek, R. Farmer, N. Hatziargyriou, I. Kamwa, P. Kundur, N. Martins, J. Paserba, P. Pourbeik, J. Sanchez-Gasca, R. Schulz, A. Stankovic, C. Taylor, and V. Vittal, "Causes of the 2003 Major Grid Blackouts in North America and Europe, and Recommended Means to Improve System Dynamic Performance", IEEE TRANSACTIONS ON POWER SYSTEMS, VOL. 20, NO. 4, NOVEMBER 2005, pp1922-1928

[8] P. Kundur, 'Power System Stability and Control', McGraw-Hill, Inc. 1994, pp 464-576.

[9] M. P. Bahrman, B. K. Johnson, "The ABCs of HVDC transmission technologies," IEEE Power \& Energy, vol. 5, April 2007, pp.32-44.

[10] D. Povh, D. Retzmann, E. Teltsch W. Fischer, L. Martin, "Use of HVDC for Power Transmission Improvements" Distributech, Conference and Exhibition,20-22Jan 2004, Orlando FL USA.

[11] R. L. Lee, et al.: "DC System Support to Southern California during Pacific AC Intertie Failures of December 22, 1982" Proceedings of the Symposium on Urban Applications of HVDC Power Transmission, Oct. 24-26, 1983, Philadelphia, USA.

[12] J. D. Wheeler, et al.: "Building India's Grid: an Examination of the Infrastructure. Benefits of HVDC Transmission", Report 14-114, CIGRE Session 2002, Paris.

[13] SEC Annual report 2009, “2009-2018 financing challenge”, http://www.se.com.sa/NR/rdonlyres/75319C375FFC-495B-9BF3-6B5EAA11F4BD/0/SaudiElectricityAnnualReport2009.pdf

[14] SEC Annual report 2008, “ 2020 Ambitious Energy strategy”, http://www.se.com.sa/NR/rdonlyres/0CAC470025B2-46A7-B0D4-E8FDA00823B0/0/SECAnnualReport2008English.pdf .

[15] Jayant Kumar, Kah-Koeng and Gerald Sheble, "AGC simulator for price based operation Partl", IEEE Transactions on Power Systems, vol.12,no.2, May 1997,pp. 527-532.

[16] Jayant Kumar, Kah-Hoeng and Gerald Sheble, "AGC simulator for price based operation part-2", IEEE transactions on Power Systems, Vol.12, no. 2, May1997, pp 533-538.

[17] Laith Al-Bassam Khaled Al-Ghamdi Ahmed Abu-Elseoud, "Tracking transmission system performance within Saudi Electricity Company (SEC) Network”, C I R E D 19th International Conference on Electricity Distribution Vienna, 21-24 May 2007 Paper 0022.

[18] Al-Alawi, J., Sud, S., McGillis, D., "Planning and design of the Gulf states interconnection. In: Power in the Gulf", Middle East Electricity Conference, January 13, 1992, pp. 49-68 (1992)

[19] McGillis, D., Sud, S., “ Power systems interconnection planning and experience”,. Power Technol. Int. 43-50 (1993).

[20] Al Alawi, J., Sud, S., McGillis, D., “ Planning and design of the Gulf states interconnection”, In: IEEE, Panel Session: Middle East Policy on Electricity Infrastructure, Interconnections, and Electricity Exchanges, San Francisco, USA, July 24-28, 1994. 
IOSR Journal of Engineering

Apr. 2012, Vol. 2(4) pp: 529-537

[21] Karim, A.M.H.A., Al Maskati, N.H., Sud, S., "Status of gulf co-operation council (GCC) electricity grid system interconnection", In: IEEE, Power Engineering Society Energy Development and Power Generation Committee, Panel Session: Status of International Interconnections and Electricity Deregulation in Africa, Denver, June 6-10, 2004

[22] T. J. Hammons, "Status / prospects of interconnections in Africa / Middle East - Part2”, energize - April 2005 pp 42-45.

[23] H. Fraser, H. K. Al-Asaad, “Engaging in Cross-Border Power Exchange and Trade via the Arab Gulf States Power Grid", The Electricity Journal, Elsevier Inc., December 2008, Vol. 21, Issue 10 pp. 19-29.

[24] Sud, S., McGillis, D., Abdulghani, S.: Guidelines for the planning and design of power system interconnections. In: Role of Electricity in the Development of Arab Countries, Cigre First Regional Meeting of Arab Region, January 21-23, 1995

[25] BT Barrett, N M MacLeod, “ GCC Interconnection HVDC Link, Novel Features and exceptional Environmental Requirements", GCC Power 2008 Conference, Manama, 9-12 November, Conference Proceedings, pp.479-484.

[26] Y. Allard, D. Soulier, J. Cochrane, B. Railing, "Multi-terminal Operations Experience - Hydro-Quebec-epool Phase-II HVDC', CIGRÉ SC14, International Colloquium on HVDC and FACTS, September 1995, Montreal, Canada.

[27] . M. Claus, D. Retzmann, D. Sörangr, K. Uecker “ Solutions for Smart and Super Grids with HVDC and FACTS” , 17th Conference of the Electric Power Supply Industry, Macau, 27 - 31 October 2008

[28] D.R. Trainer, C.C. Davidson C.D.M. Oates N.M. Macleod, "A New Hybrid Voltage-Sourced Converter for HVDC”, CIGREE 2010, B4-111, F-75008 PARIS.

[29] Robert P. Schulte, “Automatic generation Control modification for present demands on interconnected power systems”, IEEE Trans. on Power Systems, August 1996,pp. 1286-1291

[30] M Ramamurthy and N K Singh, "Optimal Model Control of Multi-Area Load Frequency Control" Proceedings IFAC Symposium on Computer Application in Large Scale Power Systems, August 1979, Paper No A5-02.

[31] N.N.Benjamin and WC Chan, "3-Level Load Frequency Control of Power Systems Interconnected by Asynchronous Tie Lines" Proceedings IEE, Vol. 126, no 11, November 1979, p 1198.

[32] Machida T. "Improving transient stability of AC system by joint usage of DC System", IEEE Trans PAS 1966;PAS- 85:226-31.

[33] Peterson HA, Krause PC “Damping of power swings in a parallel AC and DC system”, IEEE Trans PAS 1966;PAS- 85:1231-9. 